\title{
Messy Ecosystems, Orderly Frames
}

\author{
Joan Iverson Nassauer
}

Joan Iverson Nassauer, FASLA, is Professor and Head of the Department of Landscape Architecture at the University of Minnesota. Her research focuses on the intersection between landscape perception and landscape ecology. Currently she is experimenting with urban landscape designs that place unfamiliar ecosystems in a familiar cultural context.

\begin{abstract}
Novel landscape designs that improve ecological quality may not be appreciated or maintained if recognizable landscape language that communicates human intention is not part of the landscape. Similarly, ecologically valuable remnant landscapes may not be protected or maintained if the human intention to care for the landscape is not apparent. Landscape language that communicates human intention, particularly intention to care for the landscape, offers a powerful vocabulary for design to improve ecological quality. Ecological function is not readily recognizable to those who are not educated to look for it. Furthermore, the appearance of many indigenous ecosystems and wildlife habitats violates cultural norms for the neat appearance of landscapes. Even to an educated eye, ecalogical function is sometimes invisible. Design can use cultural values and traditions for the appearance of landscape to place ecological function in a recognizable context. I describe several examples of cultural language "cues to care" that provide a cultural context for ecological function, and I demonstrate how these cues can be used in design.
\end{abstract}

... A continuous reframing of the phenomenon as (a) whole becomes a part serves to overcome the inertia of certainty.

-Sidney K. Robinson Inquiry in the Picturesque

\section{Ecological Function, Cultural Perception \\ $\mathrm{E}$ cological quality tends to look messy, and this poses} problems for those who imagine and construct new landscapes to enhance ecological quality. What is good may not look good, and what looks good may not be good. The distinction between function and appearance may distress idealists who regard presentation as dissembling, but it is intrinsic to the concept of design, in which each landscape is recognized as one of any number of possible designs for a particular place. Landscape architects may consult the genius of the place, but they do not expect the genius of the place to design it.

However, even designers may become strangely submissive in the face of nature's genius, sharing in a common popular delusion that nature will speak for itself - if only human beings will quit interrupting. A belief that nature needs no presentation and that presentation is essentially sinister in its intent leaves ecosystems highly susceptible to misunderstanding. Decades ago, Lowenthal and Prince (1965) instructed that people "see their terrain through preferred and accustomed spectacles." As much as our affection for the cultural concept of nature would lead us to believe otherwise, people do not know how to see ecological quality directly. We know how to see ecological quality only through our cultural lenses, and through those lenses, it may or may not look like nature (Nassauer 1992a). Nature has come to be identified with pictorial conventions of the picturesque (Howett 1988), a cultural not ecological concept. More significantly, picturesque conventions have become so integral to landscape perception that we no longer are able to accept their origin in culture (Crandell 1993). Picturesque conventions seem so intrinsic to nature that they are mistaken for ecological quality.

The difference between the scientific concept of ecology and the cultural concept of nature, the difference between function and appearance, demonstrates that applied landscape ecology is essentially a design problem. It is not a straightforward problem of attending to scientific knowledge of ecosystem relationships or an artistic problem of expressing ecological function, but a public landscape problem of addressing cultural expectations that only tangentially relate to ecological function or high art. It requires the translation of ecological patterns into cultural language (Eaton 1990 a,b). It requires placing unfamiliar and frequently undesirable forms inside familiar, attractive packages. It requires designing orderly frames for messy ecosystems.

Some might see culture as an unnecessary barrier between science and popular public attitudes that are increasingly, even cloyingly, green. When the public is highly receptive to doing the right thing for the environment, scientific answers about what is ecologically correct should be sufficient. But in fact social conventions keep the same people who dress in green slogans dressing their homes and cities in homogenous plant communities where enormous species diversity once existed, appreciating robins where once there were warblers, and recycling plastic while depleting aquifers.

Once we begin talking about the landscapes where we live everyday-about specific changes in the way the landscape will look even for the purposes of protecting or improving ecological quality-we encounter fear, anger, rejection. Why? There is a clue in an example from Minneapolis, where a goal had been established to improve water quality in the lakes that form the heart of the public park system and some of the most desirable neighborhoods in the city. 
Storm sewers in the watersheds surrounding the lakes emptied directly into the lakes, and the construction of upstream wetlands to act as settling basins for pollutants had been identified as the most efficient means of improving water quality. Here is the clue: City council, park board and task force members, and the engineers who were involved in the process that recommended construction referred to the new features as wetlands. Citizens who lived near the grassy open spaces that were the proposed construction sites referred to them as swamps. The citizens are not self-serving or arbitrary; their perceptions fit within the center of the cultural mainstream. People may care about improving ecological quality but not at the expense of the proper appearance of their own landscapes.

\section{Proper Appearance: Neatness and Ecological Function}

It may be time to add a new acronym to the planning lexicon. "Not in my back yard" (NIMBY) resists the siting of controversial land uses. The sentiment expressed here is not in my yard (NIMY). It resists changes in the way my landscape looks because of the way it may reflect on me. Aldo Leopold poetically expressed the powerful social identification of the landowner with the look of the land in 1939:

The landscape of any farm is the owner's portrait of himself.

We need to recognize that the landscapes of city dwellers' homes, neighborhoods, parks, roadsides, and businesses are public portraits of themselves. The expectation that I represent myself as a citizen in the landscape of my home is etched deeply into popular culture. In the United States it dates at least from the early 19th century (Stilgoe 1988; Pennypacker 1992). Like all highly public speech, the language of landscape does not lend itself to colloquialism. It is adaptable, taking varied forms in different eras, but it is highly attuned to propriety and resistant to fundamental change.

The dominant culture in much of North America reads a neat, or- derly landscape as a sign of neighborliness, hard work, and pride. Typically, people want to achieve or know they are expected to achieve this landscape appearance and all that it signifies about themselves. At the same time, a neat, orderly landscape seldom enhances the ecological function of the landscape.

\section{Human Intention and Design}

When we conceive of popular perceptions in this way, we think of the role of design differently as well. If I create my landscape in order to communicate with my neighbors and maintain their approval, then the language of form that I believe that my neighbor understands is of paramount importance. I may like the idea of living in a landscape that provides wildlife cover, but I am unlikely to change my own yard or advocate that the neighborhood park take on this look if I believe that people won't like it. Human inhabited landscapes operate as ecological systems, but they also operate as communication systems (Lynch 1971), and above all other information, people seek information about other people when they experience the landscape. For designers who wish to affect the pervasive landscape pattern that landscape ecology has demonstrated to be fundamental to ecological quality, knowing the everyday language for making and interpreting landscapes will be a necessity.

Special places or preserves may be presented in more arcane scientific or privately expressive language. In the everyday landscape, rather than simply designing to enhance ecological quality or even to express ecological function as form, we must design to frame ecological function within a recognizable system of form.

In the everyday landscape of North America, the recognizable system of form typically is characterized by neatness and order. While many observers have associated neatness and order with the human desire to control or dominate the landscape (Tuan 1986; Stein 1993), these characteristics are more validly interpreted as signs of sociable human intention (Nassauer 1988a). Neatness cannot be mistaken for untended nature; it means a person has been in a place and returns frequently. It means a place is under the care of a person.

In settled landscapes, urban or countryside, people expect to see the look of human intention. Where people intend indigenous plant communities or habitats to exist as gardens or preserves, and where the landscape communicates this intention by the way its looks, people are likely to understand that this is "nature" and find it aesthetically pleasing. Where those same plant communities or habitats exist without obvious signs of human intention, they may be mistaken for neglected land or be readily compromised as land awaiting development. Perception of human intention may be the difference between a nature preserve and a dumping ground, or the difference between a wetland and a slough. Designing ecosystems so that people will recognize their beauty and maintain it appropriately may depend upon including design cues of human intention.

\section{Naturalness and Care}

While a neat landscape is the unmistakable product of human intention, a natural looking landscape is more likely to be misinterpreted. Nature is a cultural concept that is frequently mistaken as an indication of ecological quality. It has no specific appearance in form and may be as readily applied to a canopied urban plaza (Kaplan 1983) or cultivated field (Nassauer 1979) as to a wilderness.

While naturalness frequently has been described on a continuum from the pristine to "the most humanly degraded end of the ecological scale" (Maser 1990), this intuitively appealing continuum can lead us to significant errors of ecological perception, which have been described earlier (Nassauer 1992a). For example, we might assume that a nature preserve represents the absence of human influence when in fact the existence of intact remnants of indigenous ecosystems depends upon human protection and management. We also might assume that design of 
landscapes to look natural is a form of deceit about the real and destructive effects of human influence. Equating design with deceit leaves no room to acknowledge how design is necessary to represent and maintain ecological function. Finally, we might assume that people know how to see ecological function, that ecosystems speak for themselves. Consequently, we might live in the landscape without knowledge of critical but invisible ecological functions. In fact, invisible ecological function must be actively represented for human experience if human beings are to maintain ecological quality.

The fact that apparent naturalness can lead to such perceptual mistakes about ecological function underscores the power of the cultural concept of naturalness. It we acknowledge the distinction between ecological function and natural appearance, we can begin to critically analyze the cultural language of naturalness and use it as a language to intentionally communicate ecological function.

A large body of landscape perception research suggests some elements of landscape language that communicate naturalness. The elements that are repeated in the conclusions of study after study are vegetation, especially canopy trees, and water (Dearden 1987; Herzog 1989; Kaplan 1983; Knopf 1987; Smardon 1988; Ulrich 1986). Furthermore, this body of research leaves no doubt that people prefer to see landscapes that they perceive as natural.

At the same time, perception of even the most fundamental elements of a natural appearance, vegetation and water, is highly contingent on cultural interpretation. Not all vegetation is equally preferred. For example, a case study of Minnesota owners of rare ecosystems found that owners of oak woodlands tend to appreciate and manage these ecosystems to maintain them, but owners of wetlands or prairies are far less likely to appreciate them. In fact they are likely to change wetlands or prairies in order to "improve" them (Buss 1994). Preference for woodlands is also subject to cultural interpretations. For example, woodlands with dense understory or very dense can- opy woodlands may not be attractive (Kaplan 1983; Knopf 1987; Schroeder 1986; Smardon 1988).

Even within the context of appreciating nature, "too much nature" or nature that falls outside cultural expectations is unappealing. In an effort to remake nature to fit cultural expectations, people care for the landscape to the detriment of indigenous ecosystems. Wetlands are mown and planted with exotic species, prairies are planted with trees, and woodlands are mown and cleared of dead wood (Buss 1994).

The naturalness that Americans appreciate today is more closely related to an 18th century concept of the picturesque and the beautiful than it is to the understanding of ecological function (Howett 1988; Robinson 1991; Bonsignore 1992; Crandell 1993). Whether one accounts for the love of a picturesque mix of a neat open ground plane with well-spaced canopy trees on rolling terrain as a consequence of evolution (Appleton 1975; Balling and Falk 1982; Kaplan and Kaplan 1982) or taste (Robinson 1991; Pennypacker 1992; Crandell 1993), the cultural concept of picturesque nature produces a landscape that looks tended, not wild. It enters the recognizable system of landscape form with powerful symbols that work beside neatness to represent human intention.

How we show we are good citizens and good neighbors by the way we care for the landscape to make it look neat or picturesque, safe or inviting, how we use the landscape to express power or wealth-these will establish the framework within which ecosystems are manipulated on a planet dominated by human beings. In an urban or countryside context, people tend to perceive landscapes that exhibit biodiversity as messy, weedy, and unkempt. A central problem in introducing greater biodiversity and heterogeneity to the urban landscape is that these characteristics tend to be mistaken for a lack of care.

\section{Orderly Frames: Cultural Symbols of Neatness and Naturalness}

When ecological function is framed by cultural language, it is not obliterated or covered up or compromised. It is set up for viewing, so that people can see it in a new way, much in the same way as Joseph Cornell set up everyday objects in his boxes (Figure 1). Describing Cornell's boxes as descendants of slot machines, Harold Rosenberg (1969) asserted that in comparison with the objects they displayed, the boxes were the artist's "most inclusive symbol," and represented the artist's "means of participating in the common life while holding himself strictly apart from it. (The artist) becomes a member of the crowd by making anonymous use of its games" (p. 78).

Landscape architects need to strike a relationship with vernacular design traditions much like that struck by Cornell: being both "a member of the crowd" and "holding himself strictly apart from it," using its symbols for a different purpose. Cues to human care, expressions of neatness and tended nature, are inclusive symbols by which ecologically rich landscapes can be presented to people and can enter vernacular culture. Working from vernacular culture is necessary to infiltrating everyday acts of landscape change and ultimately achieving radically innovative pervasive landscape structure. This paper summarizes several projects that help to develop the argument for this concept and demonstrate its implications by constructing orderly frames for messy ecosystems.

\section{Human Intention: The Look of Care Farm Fields and Suburban Yards.}

We grossly underestimate the power of landscape appearance when we fix our attention on characteristics of scenic landscapes. If we invest only the scenic with aesthetic quality, we construct a very coarse filter that leaves only rare places for our examination and fails to capture the aesthetic experiences and aesthetic conventions that shape the larger landscape matrix. In the United States, most of the countryside, suburbia, and city neighborhoods have been the detritus of this fixation on the scenic. What could possibly make a flat Illinois cornfield without fencerow or farmstead or distant grove beautiful? Farmers see beauty in the straightness of the rows, unin- 


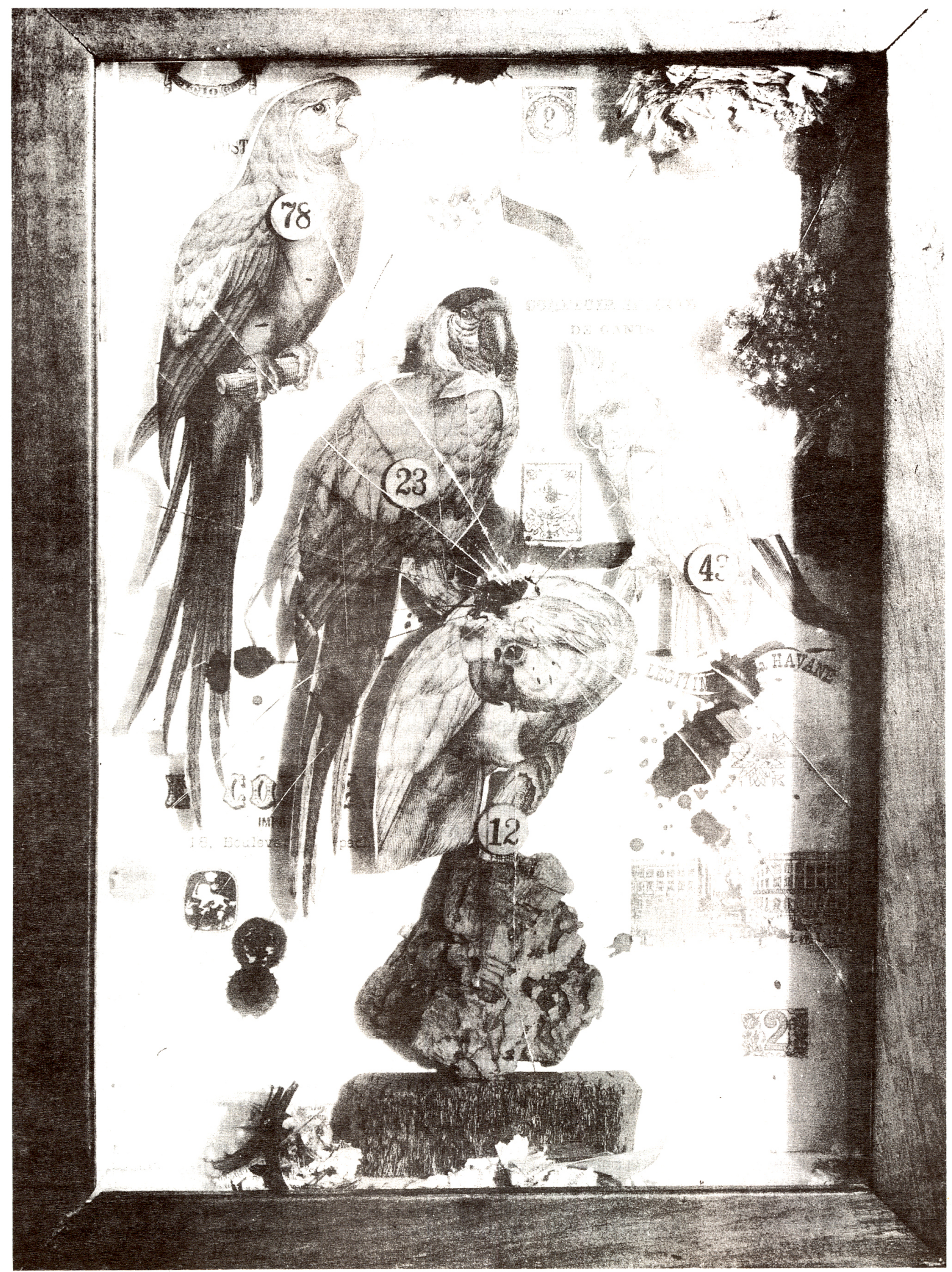

Figure 1. Joseph Cornell (American, 1903-1972) Habitat Group for a Shooting Gallery. 1943. 


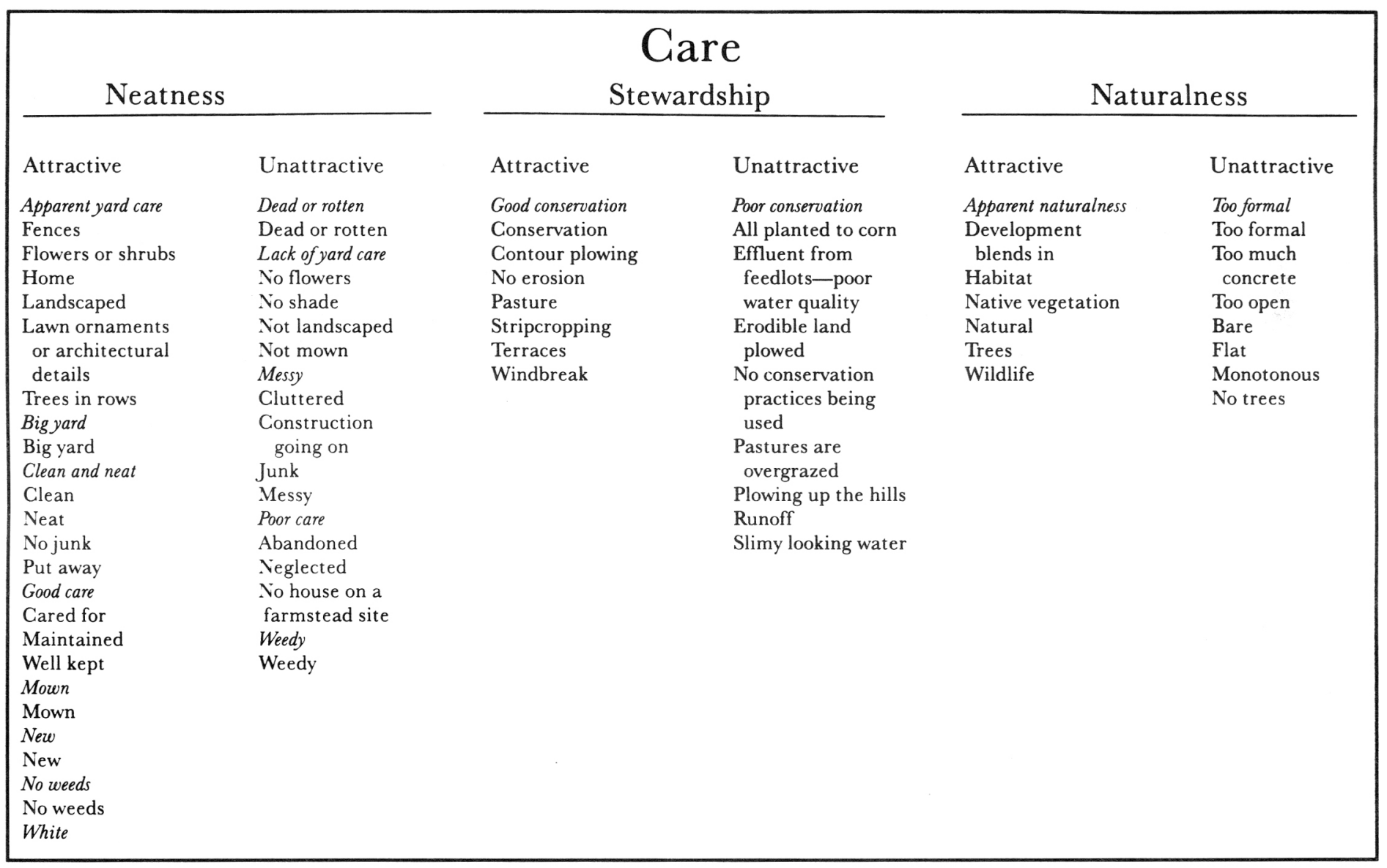

Figure 2. Content Analysis of Descriptive Terms Organized Under the Concept of Landscape Care.

terrupted by weeds or water, their even green color, and the neatly mown roadside that surrounds the field (Nassauer 1988b). These characteristics constitute a recognizable image of care so powerful that it is a stereotype that has been successfully used to violate its own original meaning-for example as a device for advertising pesticides.

In two projects in which Midwestern farmers described rural landscapes (Nassauer 1988a, 1988b), the look of care was highly associated with landscapes that farmers found attractive. While terms that were used to describe care spanned a range from the neat and tidy aesthetic of "yard care" to the cultural interpretation of "naturalness," all of the terms were summarized under the global concept of care (Figure 2). That terms like "landscaped," as applied to yard care, and "habitat," as applied to naturalness, could be organized under the look of care points to a possible means of resolving perceptual conflicts across this spectrum. Any of these perceived qualities can be the consequence of human intention to care for the land.

In the second rural landscape project (Nassauer 1988b), people who lived in the countryside but were not farmers were also interviewed. Both these people and the farmers tended to use some of the same words and the same global concept, care, to describe what made home landscapes, i.e., yards, at tractive as they did to describe what made fields attractive. Not surprisingly, two projects that focused on a suburban landscape matrix dominated by yards returned similar results.

In the first suburban project (Nassauer 1993), 234 residents of a third tier Twin Cities suburb rated video imaging simulations of seven alternative treatments of home landscapes on five dimensions: attractive- ness, care, neatness, naturalness, and apparent need for maintenance. The seven alternative treatments of home landscapes demonstrated a range of six increasingly ecologically rich landscapes designed within vernacular expectations (Figure 3): the first treatment was entirely conventional, and the succeeding five framed gardens of indigenous plant communities with cues to human intention. The seventh alternative showed the conventional landscape grown to weeds, untended (Figure 3G). While suburban residents generally preferred the immediately recognizable, conventional landscape treatment (Figure $3 \mathrm{~A})$ to all others, they rated the treatment in which half of the mown lawn had been replaced with a garden of plants indigenous to the oak savanna (Figure 3C) almost equally attractive. The weedy lawn (Figure 3G) was rated far less attractive than all other 


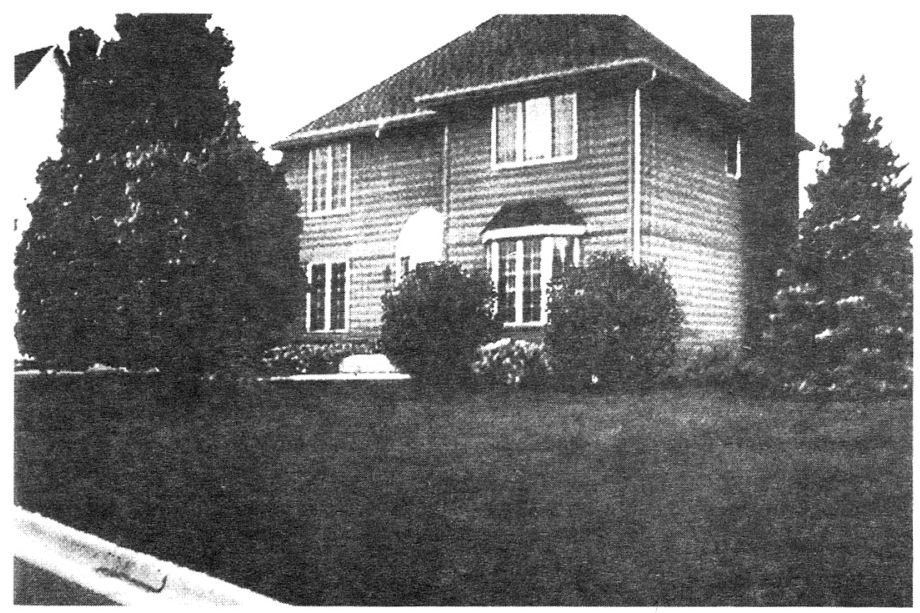

Figure 3A. Conventional lawn.

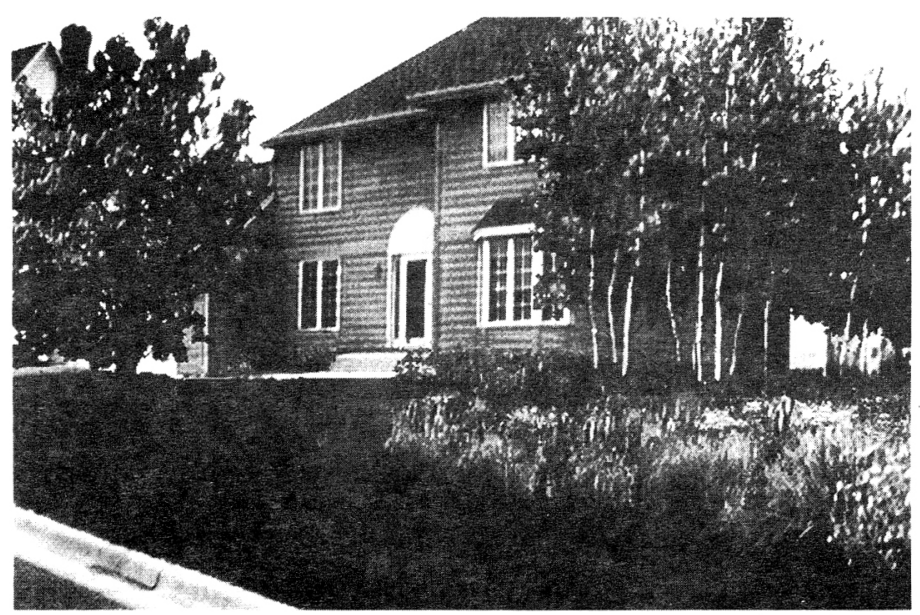

Figure 3C. Replace $50 \%$ of the front lawn with prairie garden.

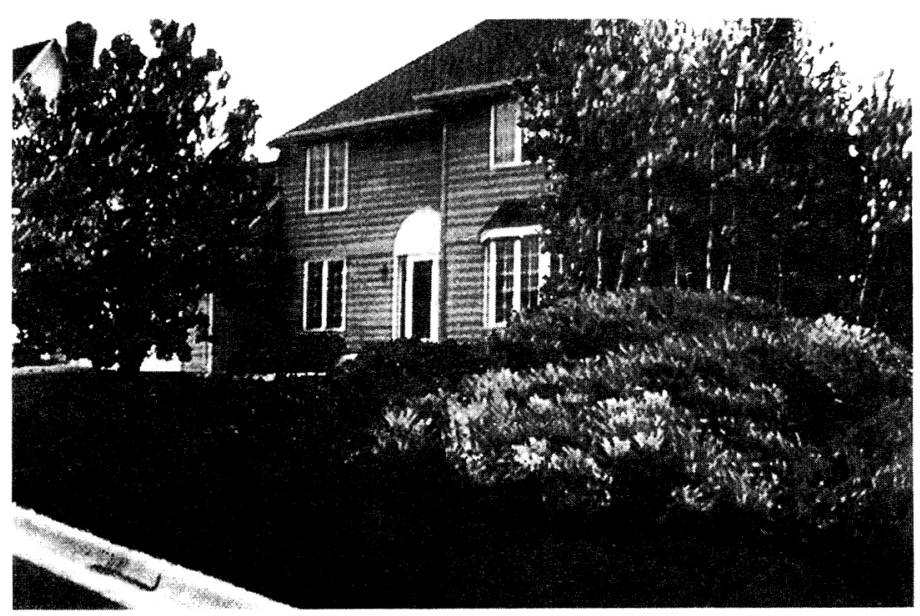

Figure $3 \mathrm{E}$. Replace $50 \%$ of the front lawn with oak savanna shrubs.

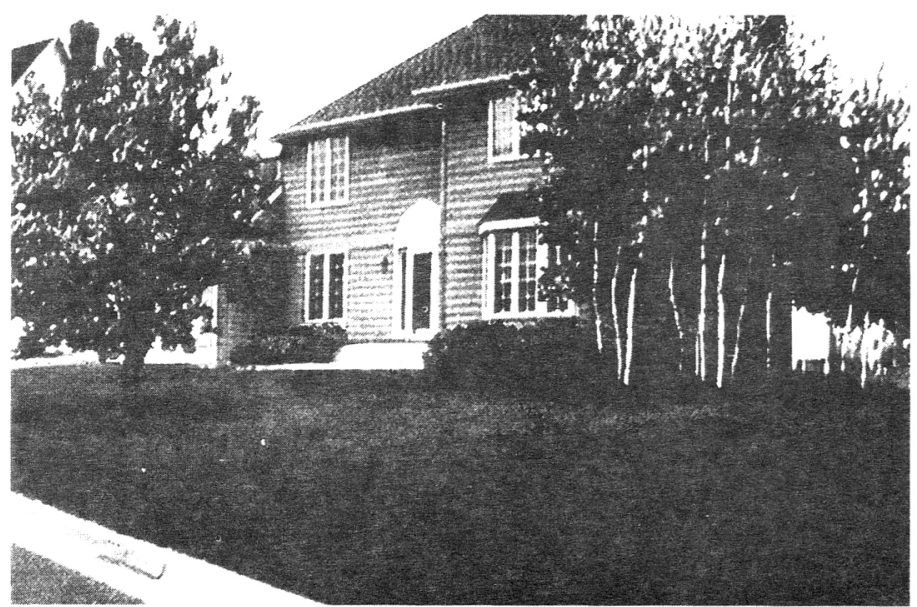

Figure 3B. Conventional lawn with native trees and shrubs.

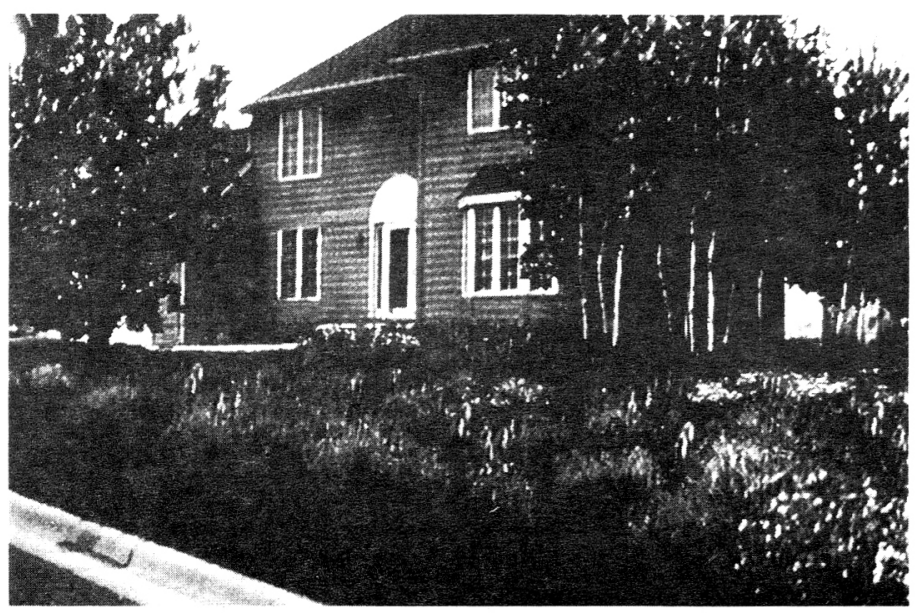

Figure 3D. Replace $75 \%$ of the front lawn with prairie grass.

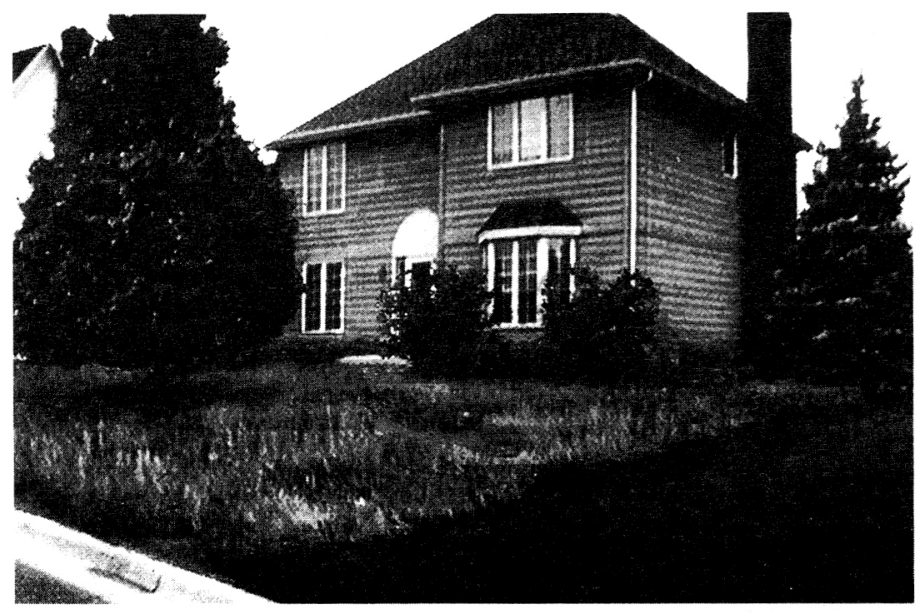

Figure 3F. Replace $75 \%$ of the front lawn with prairie garden and woodv shrubs. 


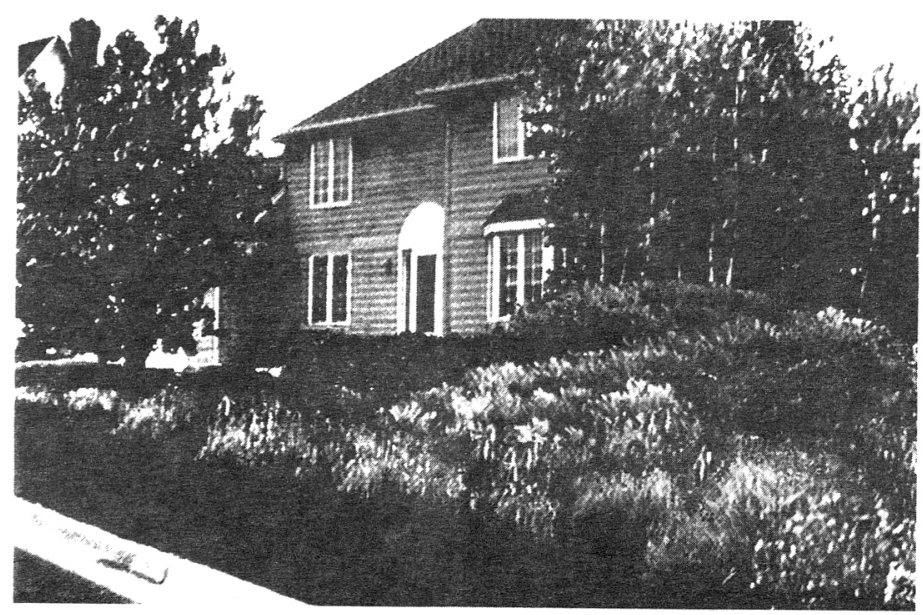

Figure 3G. Conventional lawn without mowing or pruning: the weedy lawn.

treatments, including the most ecologically rich design (Figure 3F).

More instructive for designers of human inhabited ecosystems was the association among the five characteristics. In the conventional treatment and the alternative treatments that maintained a strong resemblance to the conventional (Figures 3A-C), care and neatness scores were associated with attractiveness. Naturalness joined that association where half the lawn was replaced by the indigenous garden (3C). The characteristics were associated in the same way for the weedy lawn (3G), but on opposite ends of the scale. The weedy lawn looked unattractive, uncared for, and messy, but it did look natural and as if it required little maintenance. Where more than half the lawn was replaced by the indigenous garden or where the garden was composed entirely of dense indigenous shrubs, the clustering of characteristics was different. Neatness was no longer associated with care and attractiveness. For designers the results suggest that novel suburban landscapes are more likely to be attractive if they look neat and well cared for.

The second suburban landscape project was designed to learn about how people perceived wildlife habitat in their own neighborhoods (Martin 1993). Ethnographic interviews and, later, a complete population survey were conducted in suburban neighborhoods adjacent to the largest urban national wildlife refuge in the
United States, the Minnesota River Valley National Wildlife Refuge. Suburban residents said that people who had an attractive yard were neat, cared about the appearance of the neighborhood or about the environment, and took pride in their home or their neighborhood. People who had unattractive yards were believed to not care, to have negative personality traits (to be "different," to have no taste, etc.), or to lack resources to care for their yard. They were also described as not being good neighbors (Martin 1993). In a factor analysis of the 258 terms that suburban residents used to describe attractive and unattractive landscapes in their neighborhoods, four of the eight most powerful factors (cumulative percent of variance $=32.6 \%$ ) related to care and "landscaping." The other four factors related to attractiveness and naturalness. In these suburban neighborhoods, terms like "park-like, a blend of the natural and unnatural," were associated with naturalness. While people found "bare, severe, or unnatural" landscapes unat tractive, they also found landscapes that were "too wild, too countrylike" unattractive. "Wildlife habitat" was a term used by some people to describe what made a landscape attractive and by others to describe what made it unattractive.

Both of the suburban projects support the conclusion that "neat- ness" labels a landscape as well cared for, and that "naturalness" is defined by cultural expectations. Trees, shrubs, flowers, and grasses look at tractive unless there is "too much." Then the immediate cues to care, the presence of human intention, are lost.

Cues to Care

... Words are never our own... lan-
guage is one strategic part of the total
social fact.

-Ron Silliman, quoted in Jessica Prinz

Art Discourse/Discourse in Art

Cues that indicate human intention are cultural symbols that can be used to frame more novel ecosystems in inhabited landscapes. Using cues to care in design is not a means of maintaining traditional landscape forms but rather a means of adapting cultural expectations to recognize new landscape forms that include greater biodiversity. Cues to care make the novel familiar and associate ecosystems that may look messy with unmistakable indications that the landscape is part of a larger intended pattern. The cues may vary from region to region and among ethnic groups, but an underlying principle across cultures and regions is that these cues express care of the landscape. For example, care may be apparent in straight, weed-free rows of corn on a farm in the Midwest, but it may be apparent in an intricate pattern of gourd vines intercropped with corn planted in mounds in dryland farming by the Acoma people in New Mexico. In some places, care will not look neat in the way we might recognize it in a North American suburb. However, cues to care can be observed in the vernacular landscapes of many communities. To identify them, ask yourself the same question that people ask when they are appraising their own yards and neighborhoods: Does it look like they're taking care of it? Then, study the landscape. What makes it look well cared for?

Cues that emerged in the Midwestern studies cited here are:

Mowing. While the omnipresent, large, continuous lawn is not necessary to communicate care, mowing a 


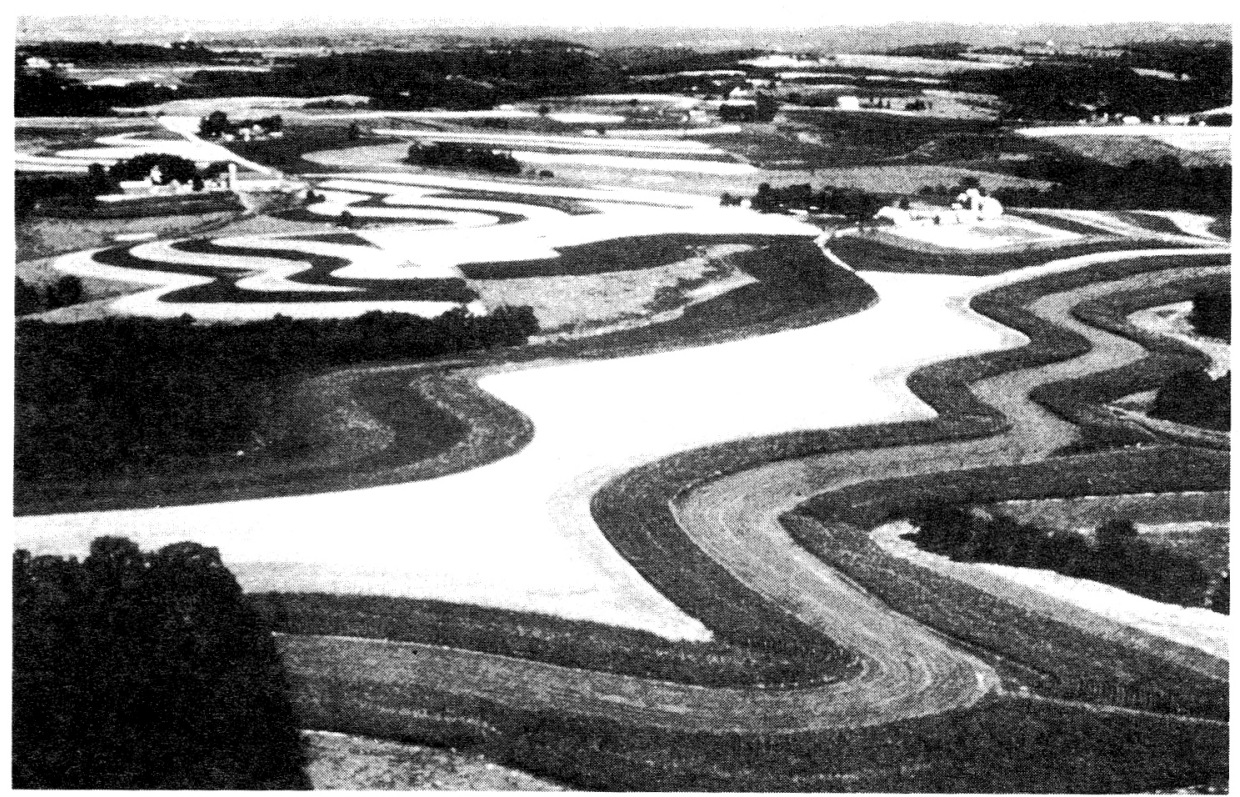

Figure 4 . The vivid pattern of stripcropping is a cue to care.

strip along human paths (streets, walkways) frames patches of greater biodiversity with clear signs of human intention.

Flowering Plants and Trees. Wetland and prairie plants with small flowers tend to be misunderstood for weeds. If restorations or gardens include an "unnaturally high" proportion of plants with larger, brighter flowers, at least in the first few seasons, people are more likely to find them attractive. Compared with shrubs or grasses, people are more likely to immediately appreciate trees, especially those they themselves can maintain in some way.

Wildlife Feeders and Houses. People widely appreciate songbirds, and while people may not be able to identify the necessary habitat for the birds they enjoy, and they may not find the "brushy" quality of the habitat attractive, they do associate bird houses and feeders with the birds they enjoy. The feeders and houses are structural cues to care for wildlife and habitat.

Bold Patterns. The rural landscape studies described above strongly suggested that the bold, clearly-visi- that foundation plantings are a nearly unassailable cultural expectation for the home landscape. They should cover the foundation of the house but they should not obscure its windows or doors to fit within the vernacular.

\section{Designs to Frame Messy Ecosystems}

Two projects that incorporated cues to care are briefly described below. In the first project, cues to care were used to frame habitat patches that were established as part of the USDA Conservation Reserve Program (CRP). Since 1986, 36.4 million acres of formerly cultivated farmland has been enrolled in the CRP. Despite the enormous habitat and soil conservation benefits that were immediately achieved by the program, people in rural communities were critical of the "weedy, messy" appearance of land in the program (Nassauer $1989 \mathrm{a}, \mathrm{b}$ ). To address these criticisms, aesthetic conservation to "communicate the appearance of good stewardship" was added to technical guidelines for implementing the CRP after 1990. Cues to care were used to design model landscapes that communicate the appearance of good stewardship for the USDA Soil Conservation Service (Figure 5). Mow strips, bold strip patterns of perennial cover at the recognizable scale of strip cropping, and the use of seed mixes heavily loaded with native forbes all helped to maintain habitat and soil conservation goals, but did so within the familiar language of care for the agricultural landscape.

A second project used cues to care to frame a created wetland in an urban park (Figure 6). The Phalen Wetland Amenity Park is retrofitted on a site that is currently a shopping center (and was a wetland forty years ago) in a stable working class neighborhood of St. Paul, Minnesota. The plan for the park frames the proposed wetland with bold, crisp bands of wet meadow plants that will drift with time but initially will introduce local people to the appearance of a wetland garden. Prairie grasses and forbes pour down an enormous south facing lawn from which people will view the wetland. While the conventional 
appearance of the lawn establishes that the wetland park is well maintained for people, the prairie grasses filter runoff from lawn and road chemicals before water reaches the wetland.

\section{Conclusions}

For new forms of ecologically rich landscapes to be sustained, the forms must be recognized and perpetuated by people in everyday situations, maintaining the landscape and creating their own landscapes. Designing orderly frames is one way of using the vernacular language of landscape to create greater ecological quality. Orderly frames bring novel landscape structures into highly stable social conventions just as Joseph Cornell's boxes allowed the artist to "participate in the common life" and "become a member of the crowd" while using the symbols of the common life for a different purpose (Figure 1) (Rosenberg, 1969). Orderly frames show that design with ecology can be motivated and perpetuated by the most ordinary human desires and habits.

This way of incorporating human nature into a concept of ecological responsibility is very different from requiring human beings to be confronted with ecologically destructive behavior. An "in your face" approach to displaying ecological function would logically extend to exposed septic systems, a landfill in every yard, corporate headquarters sited at chemical dumps, and a sense of ecological justice about natural disasters like flooding and drought. It requires people to accept what they regard as ugly or uncomfortable in exchange for what is attractive and familiar.

Using vernacular language to present unfamiliar ecosystems is also very different from purists' rejection of resource-consuming patches within the larger landscape matrix. Rather it strategically positions small pieces of the old landscape matrix of turf and annual flowers as signposts along an evolving popular landscape aesthetic. It also protects even the most pristine landscapes by clearly labeling them as under human care.

Neither penance nor purism are likely substitutes for the pride and pleasure that people take in familiar

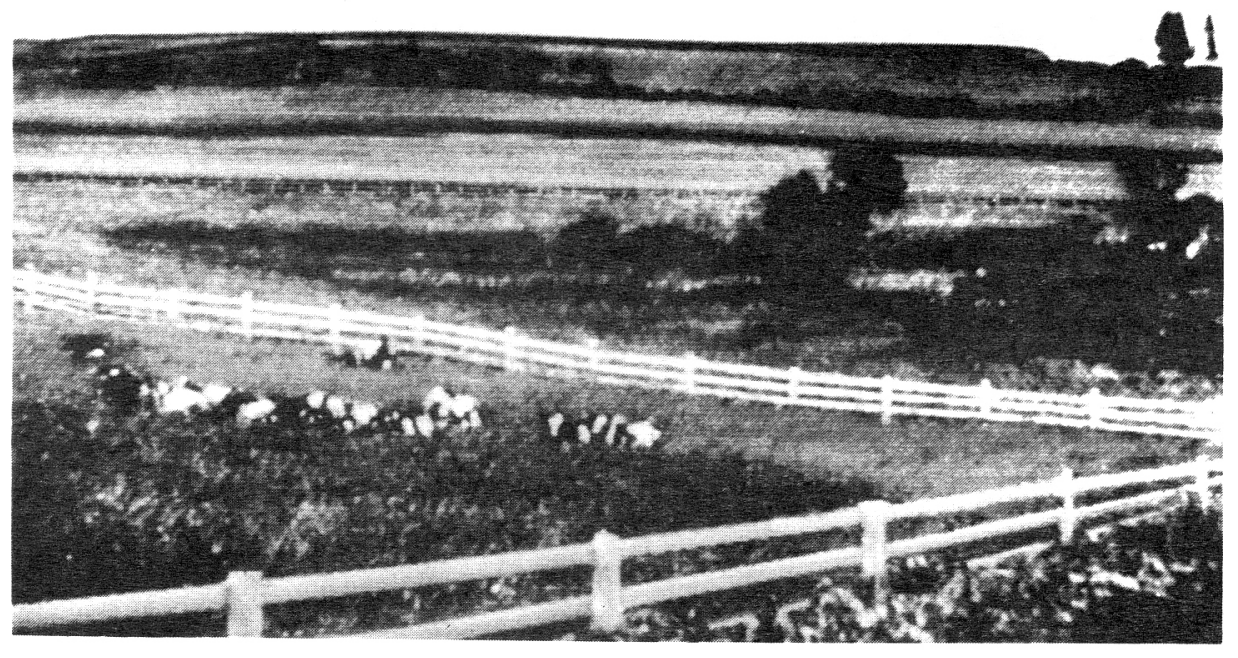

Figure 5: Model conservation landscape designed to communicate the appearance of good stewardship.

landscape patterns. Over the decades of the life of any designed landscape, penance or purism is unlikely to work. What will work is to acknowledge that cultural expectations and human pleasure will continue to be measures of ecological function, at least in everyday experience. Orderly frames are not a means of dominating ecological phenomena for the sake of human pleasure. Orderly frames can be used to construct a widely recognizable cultural framework for ecological quality.

\section{References}

Appleton, J. 1975. The Experience of Landscape. New York: John Wiley and Sons.

Balling, J. D., and J. H. Falk. 1982. "Development of Visual Preferences for Natural Environments." Environment and Behavior 14: 5-28.

Bonsignore, R. B. 1992. Representing the Ecological Function of Midwestern Farm Streams: Price's Picturesque Applied to Stream Corridors. Unpublished thesis. University of Minnesota.

Buss, S. 1994. Private Landowner's Values for Rare Species and Natural Communities. Unpublished thesis. University of Minnesota.
Crandell, G. 1993. Nature Pictorialized. Baltimore: Johns Hopkins University Press

Dearden, D. 1987. "Consensus and a Theoretical Framework for Landscape Evaluation." Journal of Environmental Management 34: $267-278$

Eaton, M. M. 1990a. Aesthetics and the Good Life. London: Farleigh Dickinson University Press.

. 1990b. "Responding to the Call for New Landscape Metaphors." Landscape Journal 9(1): 22-27.

Herzog, P. R. 1989. "A Cognitive Analysis of Preference for Urban Nature." Journal of Environmental Management 9: 27-43.

Howett, C. 1988. "Systems, Signs, and Sensibilities: Sources for a New Landscape Aesthetic." Landscape Journal 6: 1-12.

Kaplan, R. 1983. "The Role of Nature in the Urban Context." In Altman and Wohlwill, eds. Behavior and the Natural Environment. New York: Plenum Press.

Kaplan, S., and R. Kaplan. 1982. Cognition and Environment: Functioning in an Uncertain World. New York: Praeger.

Knopf, R. 1987. "Human Behavior, Cognition, and Affect in the Natural Environment." In Stokols and Altman, eds. Handbook of Environmental Psychology. New York: Wiley.

Leopold, A. 1939. "The Farmer as Conservationist." American Forests 45: 296-297.

Lowenthal, D. and Prince, H. C. 1965. "English Landscape Tastes." The Geographical Review 55: 186-222.

Lynch, K. 1971. Site Planning. 2d. ed. Cambridge: MIT Press.

Maser, C. 1990. "On the "Naturalness" of Natural Areas: a Perspective for the Future." Natural Areas Journal 10:129-133. 


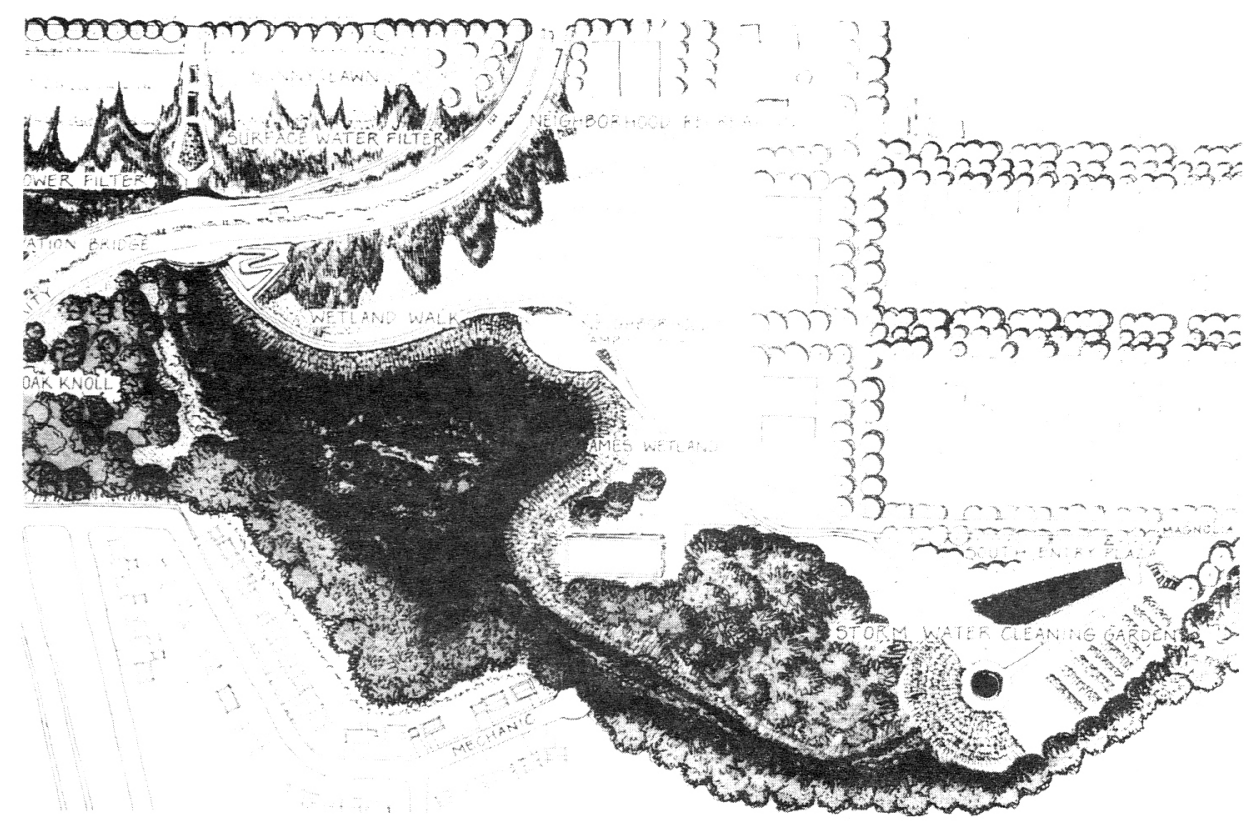

Figure 6: In the Phalen Wetland Park, crisply delineated bands of wet meadow zone plants identify the wetland as the product of human care.

Martin, R. D. 1993. Suburban Residents' Perception of Wildlife Habitat Patches and Corridors in Their Neighborhoods. Unpublished thesis. University of Minnesota.

Nassauer, J. I. 1993. "Ecological Function and the Perception of Suburban Residential Landscapes." In P. H. Gobster, ed. 55-60. Managing Urban and High Use Recreation Settings. St. Paul, MN: General Technical Report, USDA Forest Service, North Central Forest Experiment Station. ture: Neatness as a Form of Care." Hort Science 23: 973-977.

Nassauer, J. I., and R. Westmacott. 1987. "Progressiveness Among Farmers as a Factor in Heterogeneity of Farmed Landscapes." In M. G. Turner, (ed.), 199-210. Landscape Heterogeneity and Disturbance. New York: Springer-Verlag. 1979. "Managing for Naturalness in Wildlands and Agricultural Lands." In Our National Landscape, 447-453. USDA General Technical Report PSW-35. Berkeley: Pacific Southwest Forest and Range Experiment Station.

Pennypacker, E. 1992. "What is Taste, and Why Should I Care?" Proceedings of the Council of Educators in Landscape Architecture 4:63-74.

Prinz, J. 1991. Art Discourse/Discourse in Art. New Brunswick: Rutgers University Press.

Robinson, S. K. 1991. Inquiry Into the Picturesque. Chicago: University of Chicago Press.

Rosenberg, H. 1969. Artworks and Packages. New York: Horizon Press.

Rozumalski, F. J. 1992. The Wet Meadow Zone. Design to Influence Wetland Perception. Unpublished thesis. University of Minnesota.

Schroeder, H. W., and L. M. Anderson. 1984. "Perception of Personal Safety in Urban Recreation Sites." Journal of Leisure Research 16: 178-194.

Schroeder, H. W. 1986. "Establishing Park Tree Densities to Maximize Landscape Aesthetics." Journal of Environmental Management 23:

Smardon, R. C. 1988. "Perception and Aesthetics of the Urban Environment: Review of the Role of Vegetation." Landscape and Urban Planning 15: 85-106.

Stein, Sara. 1993. Noah's Garden. Boston: Houghton Mifflin Company.

Stilgoe, J. R. Borderland. 1988. New Haven: Yale University Press.

Tuan, Y. 1986. Dominance and Affection: The Making of Pets. New Haven: Yale University Press.

Ulrich, R. S. 1986. "Human Responses to Vegetation and Landscapes." Landscapes and Urban Planning 13: 29-44. 